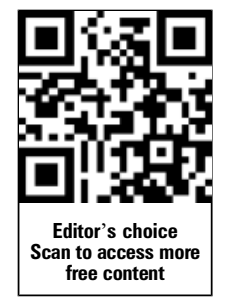

${ }^{1}$ Sports Medicine Unit, Internal Medicine and Geriatrics Institute, Catholic University of Sacred Heart, Rome, Italy ${ }^{2}$ University College London Institute for Sport, Exercise \& Health, London, UK ${ }^{3}$ Institute of Sports Medicine and Science, Italian Olympic Committee, Rome, Italy

Correspondence to Dr Bianco Massimiliano, Sports Medicine Unit, Internal Medicine and Geriatrics Institute, Catholic University of Sacred Heart, Largo Agostino Gemelli, 8,Rome 00168, Italy; massimiliano.bianco@ fastwebnet.it

Received 12 September 2012 Revised 28 November 2012 Accepted 18 December 2012 Published Online First 12 January 2013
To cite: Bianco $\mathrm{M}$ Loosemore $\mathrm{M}$, Daniele $\mathrm{G}$, et al. Br J Sports Med 2013:47:452-457.

\title{
Amateur boxing in the last 59 years. Impact of rules changes on the type of verdicts recorded and implications on boxers' health
}

\author{
Massimiliano Bianco, ${ }^{1}$ Mike Loosemore, ${ }^{2}$ Gianlorenzo Daniele, ${ }^{1}$ Vincenzo Palmieri, ${ }^{1}$ \\ Marcello Faina, ${ }^{3}$ Paolo Zeppilli ${ }^{1}$
}

ABSTRACT

Background/aim Several changes have occurred in Olympic boxing $(\mathrm{OB})$ in the last few decades, influencing the results in official competitions. The aim of this study was to assess how the evolution of rules changed the rate of the results that can influence boxers' health. Methods From a web-research, the results of $\mathrm{OB}$ tournaments from 1952 to 2011 were reviewed (29 357 bouts). For each event, rate of knockout (KO), refereestop contest (RSC), RSC-Head (RSCH), RSC-Injury (RSCI), RSC-Outclassed (RSCO), abandon, disqualification and points decisions were recorded. In our analysis we investigated the changes that occurred after the introduction of the standing-count rule (1964), mandatory head guard (1984), computerised scoring system (1992), RSCO (2000-2009) and modification of bout formula $3 \times 3$ min rounds $(3 \times 3$, until 1997 , $5 \times 2$ min rounds $(5 \times 2)$ until $1999,4 \times 2$ min rounds $(4 \times 2)$ until 2008, $3 \times 3$ from 2009).

Results The most important results were: (1) an RSCl rate increase $(0.72-2.42 \%, p<0.03)$ after the standingcount rule; (2) a lower $\mathrm{RSCl}(0.60 \%, \mathrm{p}<0.001)$ and higher RSCH $(1.31-4.92 \%, p<0.001)$ and RSC $(9.71-$ $13.05 \%, p<0.03)$ rate with mandatory head guard; (3) a KO rate reduction $(6.44-2.09 \%, p<0.001)$ with the computerised scoring system; (4) an RSC (13.15-5.91\%, $\mathrm{p}<0.05)$ and $\mathrm{RSCH}(4.23-1.41 \%, \mathrm{p}<0.001)$ rate reduction comparing $5 \times 2-4 \times 2$ bouts.

Conclusions In the last six decades, along with rule changes in $\mathrm{OB}$, a clear reduction of health challenging results was observed. In the near future, older rules will be adopted (no head guard and a manual scoring system). Continued medical surveillance is important to ensure that new rule changes do not result in poor medical outcomes for the boxers.

\section{INTRODUCTION}

Boxing is an ancient sport; wall paintings from Ethiopia and ancient Egypt suggest that it is well over 4000 years old. Boxing was first introduced into the ancient Olympic Games in 688 BC. $^{1}$ Boxing as we know it today developed in England in the 18th and 19th centuries. In 1814, to regulate the sport, the London prize fight rules were introduced and, in 1867, the Queensbury rules were first published. The first amateur contests took place in 1860 and the amateur boxing Association started in London in $1880 .^{2}$ Since this time the two codes have diverged: professional boxing (based in the tradition of prize fighting) has several sanctioning bodies which make the rules and a multitude of champions and belts, while amateur boxing is regulated only by the Amateur International Boxing Association (AIBA), an International Federation within the International Olympic Committee (IOC). The IOC has sanctioned contests at Olympic Games since 1904 (St Louis). In the last century, several changes occurred in amateur boxing not only to increase the safety of the boxers, but also to meet audience and media expectations. The most important rule changes in the last few decades are shown in figure 1.

Although international amateur boxing is a wellregulated sport practised in many countries worldwide, there are still concerns about safety and some medical organisations call for a ban on boxing. ${ }^{3-6}$ However, at this time there is no strong scientific evidence that amateur boxing is associated with serious health consequences and, in particular, with chronic traumatic brain injury. ${ }^{7} 8$ As a result, amateur boxing has been defined as a safe sport. ${ }^{9}$

A surrogate measure of the acute consequences of boxing can be made from looking at the results of boxing contests, particularly those which were stopped before the scheduled rounds had been completed. A knockout $(\mathrm{KO})$ is recorded if a boxer cannot continue within $10 \mathrm{~s}$ of a blow from an opponent. If the referee decides that the boxer is unable to defend himself adequately and is getting or may get injured, then a referee-stop contest (RSC) decision is taken. Where this occurs from a blow to the head, then a RSC head (RSCH) decision is recorded. If an injury occurs to a boxer (ie, a dangerous cut, a fracture, a dislocation, etc) then, together with the ringside doctor, the referee can stop the contest and the recorded decision is RSC injury (RSCI). Finally, from 2000 to 2009 the RSC outclassed (RSCO) decision was recorded when the points' gap between the two contenders was 20 points, suggesting that one athlete was outclassing the opponent.

The aim of this study was to assess how the evolution of rules in modern Olympic boxing has influenced, and continues to influence, the prevalence of one result over another paying particular attention to decisions that can influence boxers' safety and health. To test this hypothesis the results of official amateur boxing tournaments held in the last 59 years were reviewed.

\section{MATERIALS AND METHODS}

From a worldwide web search ${ }^{10-12}$ the results of official amateur boxing tournaments held from January 1952 to December 2011 (59 years) were reviewed. These tournaments included 15 Olympic 
Figure 1 Major rule changes in amateur boxing from 1952 to 2011. In the upper part of the panel the bout length formula has been indicated. In the upper and lower parts are shown the different subgroups in which the boxing bouts were divided for the analysis. RSCO, referee stops contest outclassed.

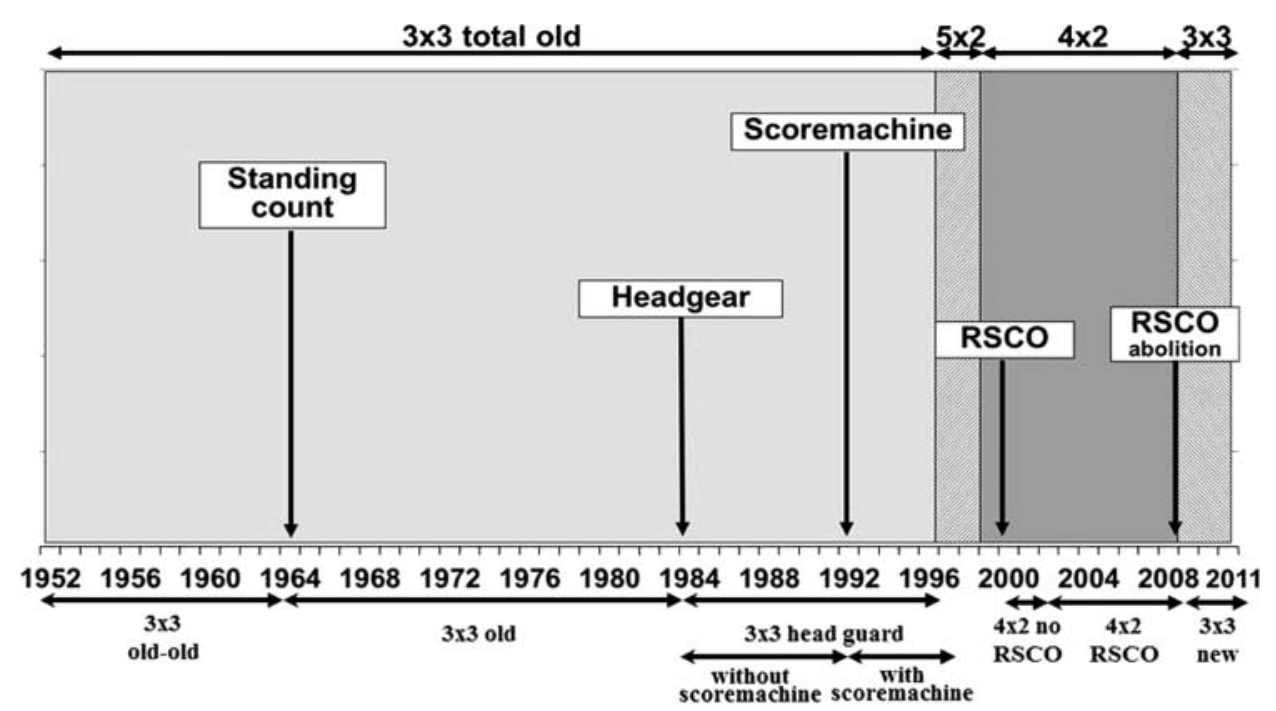


$2.42 \pm 2.51 \%$ (CIs $1.42 \%$ to $2.88 \%$ ) in $3 \times 3$ old contests. In the following years, also after the introduction of other rules, the RSCI rate was lower: $0.60 \pm 0.98 \%$ in $3 \times 3$ head guard (CIs $0.17 \%$ to $1.17 \%$ ), $1.17 \pm 1.88 \%$ in $5 \times 2$ (CIs $0.04 \%$ to $2.31 \%$ ), $0.95 \pm 1.35 \%$ in $4 \times 2$ no RSCO (CIs $0.38 \%$ to $1.88 \%$ ), 1.33 $\pm 1.70 \%$ in $4 \times 2$ RSCO (CIs $0.93 \%$ to $1.76 \%$ ) and $1.45 \pm 1.12$ in $3 \times 3$ new (CIs $0.98 \%$ to $1.94 \%$ ).

\section{Mandatory head guard (1984)}

After the introduction of mandatory head guard, there was a significant reduction of RSCI (from 2.04 $\pm 2.35 \%$ in $3 \times 3$ old-old $+3 \times 3$ old, CIs $1.26 \%$ to $2.47 \%$, to $0.60 \pm 0.98 \%$ in $3 \times 3$ head guard, CIs $0.17 \%$ to $1.17 \%, \mathrm{p}<0.001)$ and $\mathrm{KO}$ (from $6.31 \pm 5.65 \%$ in $3 \times 3$ old-old $+3 \times 3$ old, CIs $5.45 \%$ to $8.41 \%$, to $3.78 \pm 3.99 \%$ in $3 \times 3$ head guard, CIs 2.23 to $4.71 \%$, $\mathrm{p}<0.03$ ) rates, balanced, however, by a higher rate of $\mathrm{RSCH}$ (from $1.31 \pm 4.05 \%$ in $3 \times 3$ old-old $+3 \times 3$ old, CIs $0.19 \%$ to $2.06 \%$, to $4.92 \pm 5.31 \%$ in $3 \times 3$ head guard, CIs $1.39 \%$ to $4.57 \%, \mathrm{p}<0.001$ ) and RSC (from $9.71 \pm 5.72 \%$ in $3 \times 3$ old-old $+3 \times 3$ old, CIs $8.98 \%$ to $12.66 \%$, to $13.05 \pm 7.77 \%$ in $3 \times 3$, CIs 9.01 to $15.39 \%, p<0.03)$. Taking together these results, a significant $(p<0.04)$ increase in the rate of contests ended before the time limit (as the sum of RSC, RSCH and $\mathrm{KO}$ rates) was observed, rising from $17.33 \pm 8.34 \%$ in $3 \times 3$ old-old $+3 \times 3$ old (CIs $16.40 \%$ to $21.34 \%$ ) to $21.75 \pm 10.70 \%$ in $3 \times 3$ head guard (CIs $14.69 \%$ to $22.62 \%$ ). A similar result was observed when comparing the $3 \times 3$ old-old (global rate of RSC, RSCH and $\mathrm{KO}$ of $14.61 \pm 4.71 \%$, CIs $12.06 \%$ to $18.26 \%$ ) to $3 \times 3$ head guard group $(\mathrm{p}<0.04)$, but no difference was observed between $3 \times 3$ old $(18.11 \pm 9.03 \%$, CIs $16.81 \%$ to $22.71 \%)$ and $3 \times 3$ head guard group. However, the difference in the rate of contests ended before time limit between $3 \times 3$ old-old and $3 \times 3$ old was not significant.

\section{Computerised scoring system (score-machine, 1992)}

Following some scandals in point decisions, in 1992 the computer scoring system was adopted. In the group $3 \times 3$ head guard, after the introduction of the score-machines' system, there was a significant $(\mathrm{p}<0.001)$ reduction of $\mathrm{KO}$ rate changing from $6.44 \pm 4.67$ (CIs $4.30 \%$ to $7.55 \%$ ) to $2.09 \pm 2.33 \%$ (CIs $1.13 \%$ to $4.24 \%$ ). No changes were observed in all the other decisions.

\section{RSCO verdict (2000)}

From 2000 to 2009 , a mean rate of $15.49 \pm 11.21 \%$ (CIs $12.13 \%$ to $17.60 \%$ ) of contests ended by the new RSCO rule. Consequently, comparing $4 \times 2$ no RSCO with $4 \times 2$ RSCO groups, the rate of bouts ended by points decreased $(\mathrm{p}<0.0001)$ from $82.56 \pm 8.73 \%$ (CIs $78.51 \%$ to $85.81 \%$ ) to 69.86 $\pm 12.29 \%$ (CIs $67.13 \%$ to $72.94 \%$ ). All other differences met after the introduction of RSCO are summarised in table 1. Noteworthy are the significant reduction of RSC, RSCH, KO and their sum with the new rule. Moreover, no significant change in the rate of contests ended before time limit was observed in comparison with the $3 \times 3$ new formula.

\section{Bout length formula}

Comparing the $3 \times 3$ total old group (ie, from 1952 to 1997) with the new $5 \times 2$ formula, a significant $(\mathrm{p}<0.03)$ reduction of $\mathrm{KO}$ rate (from $5.33 \pm 5.19 \%$, CIs $4.23 \%$ to $6.19 \%$ to 1.58 $\pm 1.48 \%$, CIs $0.65 \%$ to $2.44 \%$ ) was observed, with no significant changes in all the other decisions' rate.

From the comparison of $5 \times 2$ and the total $4 \times 2$ group (including both $4 \times 2 \mathrm{RSCO}$ and $4 \times 2$ no RSCO), a significant rate reduction was observed with the new $4 \times 2$ formula for RSC and RSCH decisions, as well as for the sum of RSC, RSCH and $\mathrm{KO}$ rates (table 1). All these differences remained significant $(\mathrm{p}<0.05)$ when splitting the $4 \times 2$ group in the subgroups $4 \times 2$ no RSCO and $4 \times 2$ RSCO (table 1 ). Comparing these two subgroups to each other, no changes were observed except for the expected difference in the rate of point verdicts and this can be partly explained by the rate of the new RSCO verdict.

Comparing the $3 \times 3$ new group to the global $4 \times 2$, no changes were observed, points decisions' rate apart; similar results were observed comparing $3 \times 3$ new with $4 \times 2$ RSCO groups (table 1). From the comparison of $5 \times 2$ group with $3 \times 3$ new, instead, a significant rate reduction in RSC, RSCH, KO and their sum was observed with the comeback to the $3 \times 3$ formula (table 1).

Finally, a comparison of the new formula $3 \times 3$ new with all the previous groups with the same bout length is summarised in table 2 .

\section{DISCUSSION}

Boxing is an ancient sport, with a worldwide following. At the last Olympic Games (London 2012), boxing was represented by 79 countries with a total of 286 athletes (36 of whom were

Table 1 Comparison of $4 \times 2$ formulas (with and without the introduction of outclassed decision) with the formulas adopted in the years immediately before and after

\begin{tabular}{|c|c|c|c|c|c|c|}
\hline & $\begin{array}{l}3 \times 3 \text { head guard } \\
(1984-1997)\end{array}$ & $\begin{array}{l}5 \times 2 \\
(1997-1999)\end{array}$ & $\begin{array}{l}4 \times 2 \text { no RSCO } \\
(2000)\end{array}$ & $\begin{array}{l}4 \times 2 \text { RSCO } \\
(2001-2009)\end{array}$ & $\begin{array}{l}4 \times 2 \\
(2000-2009)\end{array}$ & $\begin{array}{l}3 \times 3 \text { new } \\
(2009-2011)\end{array}$ \\
\hline RSCO (\%) & - & - & - & $15.49 \pm 11.21$ & $10.51 \pm 11.79$ & - \\
\hline $\mathrm{RSCl}(\%)$ & $0.72 \pm 0.84$ & $1.17 \pm 1.88$ & $1.13 \pm 1.97$ & $1.35 \pm 1.72$ & $1.28 \pm 1.79$ & $1.45 \pm 1.21$ \\
\hline $\mathrm{RSCH}(\%)$ & $4.92 \pm 5.31 *$ & $4.23 \pm 4.922^{* * *}, \dagger$ & $0.88 \pm 1.62^{* * *}$ & $1.27 \pm 2.05^{* * *}$ & $1.41 \pm 1.62 * * *$ & $0.91 \pm 1.19 * * *$ \\
\hline RSC (\%) & $13.05 \pm 7.77^{*}$ & $13.15 \pm 7.67^{*, * *}, \dagger$ & $8.42 \pm 8.85^{* * *}$ & $5.29 \pm 6.01 * * *$ & $5.91 \pm 6.38^{* * *}$ & $6.29 \pm 4.47^{* * *}$ \\
\hline KO (\%) & $3.78 \pm 3.99 *$ & $1.58 \pm 1.48 \dagger$ & $0.89 \pm 1.44$ & $0.97 \pm 1.35$ & $0.94 \pm 1.37$ & $0.70 \pm 0.89 * * *$ \\
\hline Points (\%) & $78.76 \pm 6.77$ & $74.05 \pm 9.70 * *, \dagger$ & $82.56 \pm 8.73^{* * * * *}$ & $69.86 \pm 12.29 \dagger$ & $73.59 \pm 12.71 \dagger$ & $84.92 \pm 5.84^{*}$ \\
\hline $\mathrm{RSCH}+\mathrm{RSC}+\mathrm{KO}(\%)$ & $21.75 \pm 10.70^{*}$ & $18.92 \pm 9.69 * * *, \dagger$ & $10.19 \pm 10.01 * * *$ & $7.53 \pm 6.34 * * *$ & $8.27 \pm 6.90 * * *$ & $7.89 \pm 4.76^{* * *}$ \\
\hline
\end{tabular}


Table 2 Comparison of all the formulas characterised by three round of $3 \mathrm{~min}$ each in the last six decades of amateur boxing

\begin{tabular}{|c|c|c|c|c|}
\hline & $3 \times 3$ old-old (1952-1963) & $3 \times 3$ old (1964-1984) & $3 \times 3$ head guard (1984-1997) & $3 \times 3$ new (2009-2011) \\
\hline $\mathrm{RSCl}(\%)$ & $0.72 \pm 0.84$ & $2.42 \pm 2.51^{*}$ & $0.60 \pm 0.98^{* *}$ & $1.45 \pm 1.21$ \\
\hline RSCH (\%) & $0.00 \pm 0.0$ & $1.69 \pm 4.54$ & $4.92 \pm 5.31^{*, * *}$ & $0.91 \pm 1.19^{* * *}$ \\
\hline RSC $(\%)$ & $7.06 \pm 6.14$ & $10.48 \pm 5.44$ & $13.05 \pm 7.77^{\star}$ & $6.29 \pm 4.47^{* * *}$ \\
\hline KO (\%) & $7.55 \pm 4.43$ & $5.94 \pm 5.73$ & $3.78 \pm 3.99 * * *$ & $0.70 \pm 0.89^{*, * *, * * *}$ \\
\hline Points (\%) & $78.76 \pm 6.77$ & $73.68 \pm 9.85$ & $70.66 \pm 10.34^{*}$ & $84.92 \pm 5.84^{* *, * * *}$ \\
\hline $\mathrm{RSCH}+\mathrm{RSC}+\mathrm{KO}(\%)$ & $14.61 \pm 4.71$ & $18.11 \pm 9.03$ & $21.75 \pm 10.70^{*}$ & $7.89 \pm 4.76^{*, * *, * * *}$ \\
\hline
\end{tabular}

women, competing for the first time at the Olympics) ${ }^{13}$ and 194 national federations (of 205 recognised National Olympic Committees) are currently affiliated to AIBA. ${ }^{14}$

The medical community expresses several concerns about boxing. Independent from the ethical considerations of boxing, is boxing unacceptably harmful for athletes? Since the first decades of the last century, some reports highlighted the risk of traumatic brain injury in former boxers, appearing both as cognitive impairment and parkinsonism. ${ }^{15-18}$ However, all these reports referred to single cases or to very few athletes competing many years ago (in the late 19th or the first decades of 20th century), when there were fewer safeguarding rules.

At the beginning of the last century, each boxing match could last dozens of rounds (until the bout was abandoned or the $\mathrm{KO}$ of one competitor). At this time, boxers fought with bare knuckles or with very light gloves (2-6 ounces, that is 56.70$170.10 \mathrm{~g}$ instead of 10 ounce gloves, that is $283.50 \mathrm{~g}$ currently used), without a gum-shield and with no kind of medical check. Most of these reports refer to former professional boxers, many of whom had hundreds of contests.

When medical literature has been systematically reviewed, no strong evidence clearly linking amateur boxing with chronic traumatic brain injury was found. ${ }^{7} 8$ The AIBA has been very mindful of boxers' health and through several rules' changes introduced over the last six decades, boxing has become safer. In the London 2012 Olympics, of 272 boxing matches, there was no KO, RSCH and RSCI decision, with only four bouts ended by RSC (1.5\%).

At the beginning of our analysis (Helsinki Olympic Games in 1952) amateur boxers used to compete in three rounds of $3 \mathrm{~min}$ each, without any head guards and less emphasis on safety, such as the standing count rule, RSCO decision and more detailed medical checks.

In the 1952 Games, the rate of $\mathrm{KO}$ was $17.1 \%$, compared with the London 2012 Olympics (0\%) and to the currently used rules $(0.7 \pm 0.9 \%$ from 2009 to 2011). However, in Helsinki 1952 there was no technical knock-out decision (that means no $\mathrm{RSCH}$ and RSC), suggesting that the referee did not end the contest until the boxer was knocked out. Of interest, neither the sum of RSCH, RSC and KO verdict rate in the last Games $(1.5 \%)$, nor the mean value recorded in our analysis from 2009 to $2011(7.9 \pm 4.8 \%)$ was similar to the Helsinki results.

The first important modification to the rules of amateur boxing took place in 1964 when the standing-count rule was adopted: the referee was allowed to start an $8 \mathrm{~s}$ count if a boxer was in difficulties for any reason (particularly after a blow by the opponent), without the boxer having been knocked to the canvas. Even if this rule was adopted with the purpose of safeguarding boxers' health, our analysis showed a minor and not significant reduction in $\mathrm{KO}$ rate (from $7.6 \%$ to $5.9 \%$ ), with other results of medical interests substantially unchanged, but an unexpected significant increase (table 2 and figure 2) of matches ended due to medical reasons (mainly lacerations). Only after the introduction of the mandatory head guard in the 1984 Olympics did the RSCI reduce, it was clear that the introduction of the head guard reduced facial cuts by up to $90 \% .^{9} 19$ The mean rate of RSCI decisions showed a 3.3-fold reduction after the adoption of mandatory head guard and KO rate also significantly decreased balanced, however, by a higher rate of $\mathrm{RSCH}$ and RSC (table 2; figure 2). Taking together these results, a significant increase of the rate of contests ended before the time limit (as the sum of RSC, RSCH and KO rates) was observed, rising from $17.3 \%$ to $21.8 \%$, even if this difference is partly blunted by the overlap of their CIs $(16.4 \%$ to $21.3 \%$ before and $14.7 \%$ to $22.6 \%$ after head guard introduction). One can hypothesise that the boxers, feeling more protected by the head guard, exposed themselves to blows that before the introduction of head guards, they would have avoided. It may also be the case that the new rules allowed the referee to stop the contest early before harm could befall a boxer.

There is a limited evidence demonstrating that boxing head guards reduce the impact force to the athletes' head. ${ }^{20}{ }^{21}$ Some coaches, moreover, believe that the head protector may be detrimental to boxers' health, as it can obscure peripheral vision not allowing a boxer to defend lateral blows. ${ }^{22}$ It is important to recognise that even wearing head guards, amateur boxers still have the potential to suffer significant brain injury ranging from intracranial trauma to changes in brain cellular biomarkers postfight. ${ }^{23}$ It is not clear if removing head guards would make any difference to such events. For these reasons, and to meet media and audience expectations (the head guard makes all the boxers quite similar and anonymous), the head guard will not be mandatory in international amateur boxing from 2013. ${ }^{22}$ It will be important to monitor this change, not only to see if the number of $\mathrm{KO}$ and $\mathrm{RSCH}$ increases, but also to see if the number of RSCI increases due to cuts. Our figures would predict that $\mathrm{KO}$ and RSCH will remain the same but RSCI will increase.

In 1992, following some well-publicised scandals in point decisions, a computerised scoring-system was adopted. The new rule changed the sport. It was more effective to land clear (usually single) punches, the main target being the head (a blow to the head was more easily scored by the judges than one to the body), with no importance set on the power of the blow. In this way the sport became less aggressive. Immediately after the insertion of this new rule, comparing competition of the same length and with the same rules (apart from the scoring system) 
A

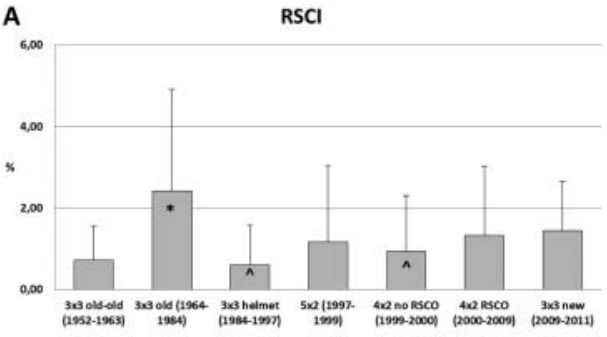

B

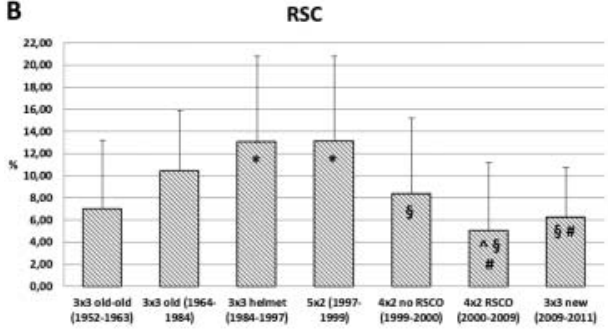

C

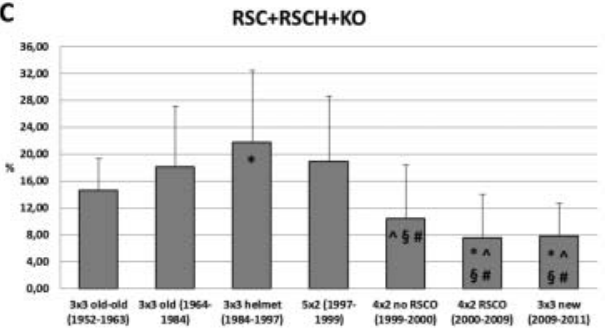

D

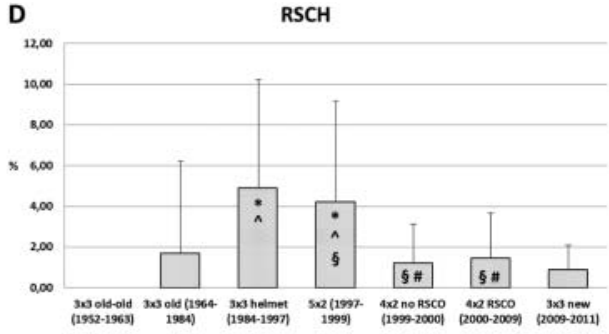

$E$
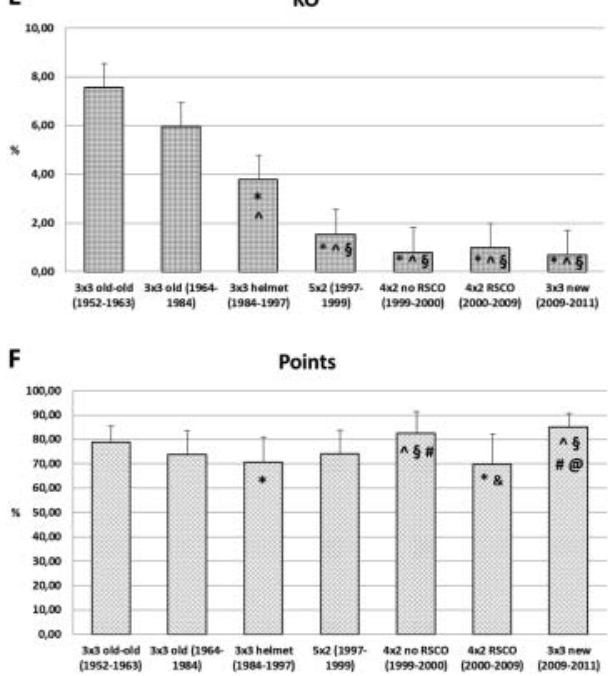

Figure 2 Comparison of different kinds of verdicts in amateur boxing from 1952 to 2011. Please note, the significant reduction of the rate of verdicts ended by points in $4 \times 2$ RSCO groups can be explained by the new rule of the outclassed, accounting for the $15.49 \pm 11.21 \%$ of all verdicts in 2000-2009 period * $p<0.05$ in comparison with $3 \times 3$ old-old; $\wedge p<0.05$ in comparison with $3 \times 3$ old; $\S p<0.05$ in comparison with $3 \times 3$ helmet; \# $p<0.05$ in comparison with $5 \times 2$; and $p<0.05$ in comparison with $4 \times 2$ no RSCO; @ $p<0.05$ in comparison with $4 \times 2$ RSCO. KO; knockout; RSC, referee stops contest for any other reason he/she believes opportune (hard blow to the body, lack of stamina, etc); RSCH, referee-stop contest due to heavy head blow(s); RSCl, RSC due to injury; RSCO RSC outclassed.

the rate of KO significantly decreased. However, the rate of bouts ended before time limits (ie, the sum of RSC, RSCH and $\mathrm{KO})$ did not change. One can hypothesise that, with the new scoring system, it was easier to record an RSC/RSCH decision. However, there is the possibility that the referees were instructed to be more cautious and to stop the contests more quickly with the main purpose to safeguard athletes' health. In those years, following some physiological reports suggesting a relatively high fatigue with the $3 \times 3$ formula, ${ }^{24}{ }^{25}$ AIBA decided to change the bout length to five rounds of $2 \mathrm{~min}$ each (from 1997 to 1999) and, then, to four rounds of 2 min (from 1999 to 2009). With the $5 \times 2$ formula, another significant reduction in $\mathrm{KO}$ rate was observed remaining more or less at these values until the present day. With the $4 \times 2$ formula, a significant reduction in RSC and RSCH rate, together with a reduced rate of matches ended before time limits was observed and it was increasingly evident after the introduction of the new rule of outclassed in 2000. This rule was adopted to safeguard athletes with evidently lower boxing skills in respect to their opponent. Boxing bouts were less spectacular and several competitions in a single tournament (mean value $15.5 \%$ ) could end by RSCO. For this reason, this rule was revoked in 2009 and, at the same time, AIBA decided to go back to the old $3 \times 3$ formula. No increase in the rate of KO, RSC, RSCH and their sum was observed. One can speculate that other factors played a role in this decade so rich in rule changes, factors certainly influenced by AIBAs' will to protect boxers' health. For example, great steps forward have been made in materials selection, with current use of safer energy-dissipating gloves and head guards. Also careful system of training for ringside officials (referees, judges, doctors, etc) is actively running at international level and in most national federations in order to guarantee the highest level of safety inside and around the ring. Recently new AIBA's rules to make boxing more spectacular have been adopted with other rule changes to follow from 2013, AIBA will start organising professional contests (AIBA Professional Boxing), allowing amateur boxers to compete in this form of professional boxing while still allowing them to return to take part to the Olympic Games. In professional boxing health risks are greater, as the athletes compete without head guards, for greater number of rounds (from 4 to 12) of 3 min each. Hand bandaging will be similar to current professional practice which gives the fist a much firmer covering.

In the last 59 years, improvements in health challenging verdicts recorded have been achieved by changes in the rules of boxing. It is of concern that the recent rule changes will be a backward step in athletes' health safety. Continued medical surveillance is important to ensure that new rule changes do not result in poor medical outcomes for the boxers. A neutral structure as a specifically designed medical commission inside the AIBA or the IOC could take care of this epidemiological monitoring.

\section{Study limitations}

This is the first study to make a comprehensive analysis of amateur boxing rules' changes over a six-decade period, trying 
to assess their influences on verdicts of possible medical interest. For the long-time interval evaluated, our analysis could not take into account some factors that surely influenced the results. We tried to split the entire time period in several subperiods characterised by the change of a single rule, so to extrapolate the real effect of that single rule. At times, however, this was not possible. In 1984, for example, following some severe eye injuries, the boxing glove shape was changed, adopting the so-called thumb-less gloves, with the thumb attached to/hidden by the hand to avoid entering the orbit.

Gloves' weight changed: until 1984, boxers used 8 ounce gloves; in the following decade, lighter boxers (up to $67 \mathrm{~kg}$ ) wore 8 ounce gloves, with the heavier athletes adopting 10 ounce gloves; in 1994 all weights used 10 ounce gloves. In the same time period several other rules were changed (mandatory head guards in 1984, computerised scoring system in 1992, $5 \times 2$ formula in 1997) and so, the result could have been affected by other confounding factors.

We were not able to evaluate other issues that have influenced the rate of results over the time, as continuous advances in materials technology have occurred, with gloves and head guards more energy dissipating than those used even a decade before.

Another issue that could have affected our results is that until 1970 the technical KO decision was adopted in the same circumstances as RSC and RSCH. As, in the following years, the majority of the matches stopped before the time limit ended with an RSC decision (3.7-fold the RSCH rate), we decided to include technical $\mathrm{KO}$ verdicts in the RSC group for statistical analysis. In this way, from 1952 to 1970 , we could have lost some decisions caused by head blows, but we used the sum of RSC, RSCH and $\mathrm{KO}$ decisions as a comprehensive marker of verdicts of medical interest.

\section{CONCLUSION}

Several changes have occurred in the rules of amateur boxing in the last 59 years and modern Olympic boxing is a quite different sport from that observed in the early 1950s. Looking at the rate of results of medical interest, a clear and significant reduction of health challenging results can be observed. There is no doubt that modern amateur boxing is a safer discipline than observed some decades ago.

From 2013, in International boxing, the head guards will be removed and computer scoring will be replaced with the old manual system.

It is of paramount importance to continue the surveillance of the trend in results of medical interest so that the international governing body can intervene immediately in case of any increase in poor medical outcomes.

\section{What are the new findings?}

- Rules' changes in Olympic boxing clearly influenced results of medical interests in the last six decades.

- After mandatory head guard rule, a significant reduction of bouts ended due to medical decision (injuries) was observed.

- With the come back to the old $3 \times 3$ bout formula length (2009), no changes were observed in results of medical interest.
How might it impact on clinical practice in the near future

- New rules' changes in international boxing will be inserted in 2013. In particular, head guards will be removed and computer scoring will be replaced with the old manual system.

- A strict surveillance of the trend in results of medical interest is fundamental to intervene immediately in the case of increase in poor medical outcomes.

Contributors Each author provided substantial contributions to (1) conception and design of the study, acquisition, analysis and interpretation of data; (2) drafting the article and revising it critically for important intellectual content and (3) final approval of the version to be published.

Competing Interests None.

Provenance and peer review Not commissioned; externally peer reviewed.

\section{REFERENCES}

1 Swaddling J. ed. The ancient Olympic Games. 3rd edn. Oxford: Oxford University Press, 2008:54.

2 Attwood A, Loosemore M, Knowles CH. Amateur boxing association of England ltd official handbook 2003. Fox Promotions Media, London, 2003:10.

3 American Medical Association. H-470.963: boxing injuries. https://ssl3.ama-assn. org/apps/ecomm/PolicyFinderForm.pl?site=www.ama-assn.org\&uri=/ama1/pub/ upload/mm/PolicyFinder/policyfiles/HnE/H-470.963.HTM (accessed 16 Aug 2012).

4 Australian Medical Association. Boxing: 1997-reaffirmed 2007. http://ama.com.au/ node/444 (accessed 16 Aug 2012).

5 World Medical Association. WMA statement on boxing. www.wma.net/en/ 30publications/10policies/b6/index.html (accessed 16 Aug 2012).

6 American Academy of Pediatrics. Committee on sports medicine and fitness. Participation in boxing by children, adolescents, and young adults. Pediatrics 1997;99;134-5.

7 Loosemore M, Knowles CH, Whyte GP. Amateur boxing and risk of chronic traumatic brain injury: systematic review of observational studies. Br I Sports Med 2008:42:564-7.

8 McCrory P, Zazryn T, Cameron P. The evidence for chronic traumatic encephalopathy in boxing. Sports Med 2007;37:467-76.

9 Jako P. Safety measures in amateur boxing. Br J Sports Med 2002;36:394-5.

10 http://amateur-boxing.strefa.pl/ (accessed 16 Aug 2012).

11 http://www.boxing.org.au/results.html (accessed 16 Aug 16 2012).

$12 \mathrm{http}: / /$ frontpageboxing.com/amateurs/usa (accessed 16 Aug 2012)

13 http://www.aiba-london2012.com/index.php/boxers (accessed 16 Aug 2012).

14 http://aiba.org/default.aspx?pld=1296\# (accessed 16 Aug 2012).

15 Martland S. Punch drunk. JAMA 1928;91:1103-7.

16 Critchley M. Medical aspects of boxing, particularly from a neurological standpoint. Br Med J 1957;1:357-62.

17 Betti CO, Ottino CA. Pugilistic encephalopathy. Acta Neurol Latinoam 1969;15:47-51.

18 Unterharnscheidt F. About boxing: review of historical and medical aspects. Texas Rep Biol Med 1970:28:421-95.

19 Zazryn TR, McCrory PR, Cameron PA. Neurologic injuries in boxing and other combat sports. Phys Med Rehabil Clin N Am 2009;20:227-39.

20 Viano DC, Casson IR, Pellman EJ, et al. Concussion in professional football: comparison with boxing head impacts-part 10. Neurosurgery 2005;57:1154-72

21 Bartsch AJ, Benzel EC, Miele VJ, et al. Boxing and mixed martial arts: preliminary traumatic neuromechanical injury risk analyses from laboratory impact dosage data. J Neurosurg 2012;116:1070-80.

22 McCrory P, Falvey E, Turner M. Returning to the golden age of boxing. Br J Sports Med 2012:46:459-60.

23 Graham MR, Myers T, Evans $P$, et al. Direct hits to the head during amateur boxing is associated with a rise in serum biomarkers for brain injury. Int $\mathrm{J}$ Immunopathol Pharmacol 2011;24:119-25.

24 Ghosh AK, Goswami A, Ahuja A. Heart rate \& blood lactate response in amateur competitive boxing. Indian J Med Res 1995;102:179-83.

25 Dal Monte A, Faina M. eds.Metodi di valutazione funzionale: applicazioni pratiche. Pugilato. In: Valutazione dell'atleta. analisi funzionale e biomeccanica della capacità di prestazione. Turin: UTET, 1999:413-16. 